\title{
Trends in age at first sex in Uganda: evidence from Demographic and Health Survey data and longitudinal cohorts in Masaka and Rakai
}

\author{
E Slaymaker, ${ }^{1}$ J B Bwanika, ${ }^{2}$ I Kasamba, ${ }^{3}$ T Lutalo, ${ }^{2}$ D Maher, ${ }^{3}$ J Todd ${ }^{3}$
}

- A figure is published online only at http://sti.bmj.com/ content/vol85/issueSuppll

${ }^{1}$ Centre for Population Studies, London School of Hygiene and Tropical Medicine, London, UK

${ }^{2}$ Rakai Health Sciences

Program, Kalisizo, Rakai,

Uganda; ${ }^{3}$ MRC/UVRI Research

Unit on AIDS, Entebbe, Uganda

Correspondence to:

Ms E Slaymaker, Centre for Population Studies, London

School of Hygiene and Tropical

Medicine, 49-51 Bedford

Square, London WC1B 3DP, UK

emma.slaymaker@Ishtm.ac.uk

Accepted 20 January 2009

\section{UNLOCKOI}

This paper is freely available online under the BMJ Journals unlocked scheme, see http:// sti.bmi.com/info/unlocked.dtl

\begin{abstract}
Objectives: To derive the best possible estimates of trends in age at first sex (AFS) among successive cohorts of Ugandan men and women based on all the data available from the Demographic and Health Surveys (DHS) and cohort studies in Masaka and Rakai districts.

Methods: The datasets from the DHS, Masaka cohort and Rakai cohort were analysed separately. Survival analysis methods were used to estimate median AFS for men and women born in the 1950s-1980s and to compute hazard ratios for first sex, comparing later cohorts with earlier cohorts.

Results: The DHS and Masaka data showed an increase in AFS in women in the more recent birth cohorts compared with those born before 1970, but this was less apparent in the Rakai data. Successive male cohorts in Masaka appeared first to have an increased AFS which subsequently decreased, a trend that was also apparent (but not significant) in the DHS data. Younger men in Rakai had an earlier AFS than those born before 1980.

Conclusions: Women in Uganda who were born after 1970 have, on average, had sex at a later age than those born earlier. For men, AFS has not changed consistently over the period in question. Differences between Masaka and Rakai may reflect socioeconomic differences. Most of the change in AFS occurred too late to have contributed to the initial decline in the incidence of HIV.
\end{abstract}

Although not a strategy that can be maintained throughout a lifetime, avoidance of sexual intercourse is a reliable way to avoid contracting most sexually transmitted infections and of preventing unwanted conceptions. Abstinence has been a key component of many HIV prevention programmes in Africa and elsewhere. ${ }^{1-3}$ Abstinence usually means encouraging young people to delay their sexual debut with the intention of reducing their exposure to sex and sexual partners before committing to a stable and hopefully long-lasting partner. For HIV prevention, implicit in this message is that this permanent partner is uninfected, or at least less likely to be infected than other more casual partners.

There is considerable interest in measuring levels and trends in the key behaviours tackled by many HIV prevention programmes: abstinence, number of partners and condom use. Age at first sex (AFS) is a key indicator for measuring behaviour change in HIV prevention programmes. ${ }^{145}$ In many developing countries, AFS and age at first marriage (AFM) have occurred at older ages in recent years compared with $40-50$ years ago. ${ }^{67}$ The reasons for these changes are complex, but there are clear links between development and delayed AFS. It is also clear that behaviour change does not occur in isolation as risk behaviour is unlikely to change unless the social context is supportive of change. The timing of first sex is a product of agency and opportunity. Individuals may have limited autonomy to delay sexual debut if their first experience of sex is through coercive sex or rape. ${ }^{8-10}$

Uganda was the first country to report a generalised epidemic and to show a decline in the prevalence of HIV among the general population. Sexual behaviour data including AFS have been collected in several Demographic and Health Surveys (DHS) over the past 15 years, ${ }^{11}$ and have been collected from two population-based cohorts in south western Uganda. There is a considerable literature on changes in sexual behaviour and their influence on the decline in HIV prevalence in Uganda during the 1990s. ${ }^{12}{ }^{13}$ This highly charged debate has largely concluded that a multifactorial response-and not one simple behaviour changewas key to the decline in prevalence. ${ }^{14} \mathrm{~A}$ secondary but crucial point is that data from the relevant time period are inadequate to settle the debate. ${ }^{16}{ }^{17}$

AFS is the only behavioural measure for which historical trends can be reconstructed using more recently reported recall data. These trends can be difficult to identify using data from a series of cross-sectional surveys because observed change could be due to differences in data quality between surveys or to changes in the composition of the population between the time of AFS and the time of the survey or between surveys. If these differences are related to AFS—for example, if those with a younger AFS tend to emigrate or to die prematurely_an artificial trend may be seen.

We determined the trends in AFS in Uganda by comparing repeated cross-sectional data from the DHS with data collected from two cohorts in rural Uganda. Changes in population structure do not affect the cohort data because information is collected on all individuals during the time they are resident in the area and retained for later analysis. The data therefore include anyone who subsequently died or moved away as well as immigrants to the area.

The quality of retrospectively reported data on AFS can be compromised by reporting bias due to accidental recall errors or through a desire to conform to health education messages. This can be assessed directly using cohort data and is discussed elsewhere in this issue. Although 
considerable variability in response is apparent, this does not have a directional effect on the results. ${ }^{18}$

\section{METHODS}

Data were used from all the DHS conducted to date in Uganda (1988, 1995, 2000/1 and 2006) and from two longitudinal population-based studies, one in Masaka district and one in Rakai district. The DHS provides robust national estimates for different time points, and the methods by which the data are collected are openly available. ${ }^{11}$ The cohort data provide detailed information for two sets of respondents from two districts of Uganda, both of which have been extensively reported in publications over the past 15 years. ${ }^{12}{ }^{19-21}$

\section{DHS}

Data were obtained for all the DHS conducted in Uganda. In 1988 only women were interviewed but in subsequent years $(1995,2000 / 1,2006)$ data are available for men and women. The geographical range of the sample was restricted in 1988 compared with the later surveys. AFS, reported in whole years, is one of the first questions asked in the section on marriage and sexual behaviour and has been asked in the same way in all surveys. We have restricted our analysis to people who were born between 1950 and 1991 and had their first sex between 1960 and 2006; 973 respondents who were born before 1950 were excluded. We have used the unedited data from the DHS and have not corrected AFS for other reported ages in the DHS (age at first marriage and age at first birth). National rather than regional data were used because the number of respondents from the region that contains Masaka and Rakai districts was inadequate for this analysis.

\section{Masaka study}

The Medical Research Council (MRC) general population cohort has been described previously. ${ }^{12}{ }^{19}$ Briefly, the study is located in a rural subcounty in Masaka district in south-western Uganda where an open cohort has participated in annual population-based surveys. In 1989 the census included 10000 people residing in 15 villages, but in 1999/2000 this expanded to 18000 residents in 25 villages. Survey staff administer a risk factor questionnaire and annually collect a blood sample for HIV testing. Starting in 1997, AFS was asked as the first question on sexual behaviour, in the same way in all surveys, and reported in whole years. For this paper, analysis was restricted to participants born between 1950 and 1994.

\section{Rakai study}

The Rakai Health Sciences Program (RHSP) has, since 1994, conducted annual surveys using an open-community cohort of consenting persons aged 15-49 years resident in rural communities of Rakai District, south-western Uganda. ${ }^{20}{ }^{21}$ Surveys are conducted annually using a questionnaire that includes modules on both sociodemographic and behavioural characteristics. The same question on AFS was asked, in completed years, at the enrolment visit of a participant during study rounds 4 (1997-8) and 6-10 (1999-2004). This analysis was restricted to participants born between 1950 and 1989 and resident in 43 communities that have been followed since 1994.

\section{Statistical methods}

For the two cohort studies, responses that were older than the age of the respondent at the time of the survey were excluded from the analysis. For each participant the most likely AFS was

Table 1 Number of male respondents by survey and year of birth, and median age at first sex (AFS) for each survey (for all DHS and for the Masaka and Rakai studies)

\begin{tabular}{|c|c|c|c|c|c|c|c|c|c|}
\hline \multirow[b]{2}{*}{ Year of birth } & \multicolumn{5}{|l|}{ DHS } & \multicolumn{2}{|c|}{$\begin{array}{l}\text { Masaka } \\
\text { cohort }\end{array}$} & \multicolumn{2}{|c|}{$\begin{array}{l}\text { Rakai } \\
\text { cohort }\end{array}$} \\
\hline & 1995 & 2001 & 2006 & Total & Median AFS $\uparrow$ & $\mathbf{N}$ & Median AFS & $\mathbf{N}$ & Median AFS \\
\hline $1950-9$ & 384 & 260 & 205 & 849 & 18.1 & 492 & 18.5 & 852 & 18.1 \\
\hline $1960-9$ & 636 & 494 & 502 & 1632 & 18.2 & 843 & 18.2 & 2060 & 17.9 \\
\hline $1970-9$ & 767 & 631 & 690 & 2088 & 18.0 & 1389 & 18.0 & 4060 & 17.8 \\
\hline $1980-9$ & 25 & 524 & 874 & 1423 & 17.9 & 2781 & 18.5 & 2821 & 17.1 \\
\hline $1990-4$ & 0 & 0 & $232^{*}$ & $232^{*}$ & $18.1^{*}$ & 933 & 17.1 & 0 & - \\
\hline Total & 1812 & 1909 & 2503 & 6224 & 18.0 & 6438 & 18.2 & 9793 & 17.7 \\
\hline
\end{tabular}

DHS, Demographic and Health Survey.

*1990-1 only.

$\nmid$ Based on data from all surveys.

Table 2 Number of female respondents by survey and year of birth, and median age at first sex (AFS) for each survey (for all DHS and for the Masaka and Rakai studies)

\begin{tabular}{|c|c|c|c|c|c|c|c|c|c|c|}
\hline \multirow[b]{2}{*}{ Year of birth } & \multicolumn{6}{|l|}{ DHS } & \multicolumn{2}{|c|}{$\begin{array}{l}\text { Masaka } \\
\text { cohort }\end{array}$} & \multicolumn{2}{|l|}{$\begin{array}{l}\text { Rakai } \\
\text { cohort }\end{array}$} \\
\hline & 1988 & 1995 & 2001 & 2006 & Total & Median AFS $\uparrow$ & $\mathbf{N}$ & Median AFS & $\mathbf{N}$ & $\begin{array}{l}\text { Median } \\
\text { AFS }\end{array}$ \\
\hline $1950-9$ & 1158 & 1171 & 777 & 360 & 3466 & 15.9 & 581 & 16.6 & 1039 & 15.9 \\
\hline $1960-9$ & 1948 & 2273 & 1604 & 1553 & 7378 & 16.1 & 1030 & 16.8 & 2196 & 16.0 \\
\hline $1970-9$ & 947 & 3199 & 2805 & 2497 & 9448 & 16.4 & 1768 & 17.0 & 5606 & 16.6 \\
\hline $1980-9$ & 0 & 131 & 2060 & 3366 & 5557 & 17.1 & 3235 & 17.5 & 4853 & 16.5 \\
\hline $1990-94$ & 0 & 0 & 0 & $755^{*}$ & $755^{*}$ & - & 829 & 16.9 & 0 & - \\
\hline Total & 4053 & 6774 & 7246 & 8531 & 26604 & 16.4 & 7443 & 17.1 & 13694 & 16.4 \\
\hline
\end{tabular}

DHS, Demographic and Health Survey.

*1990-1 only.

†Based on data from all surveys. 
calculated as the age reported in $50 \%$ or more of the survey responses, or the mean age if no age was reported in $50 \%$ of the surveys. Stata Version 10 (Stata Corp, College Station, Texas, USA) was used for all analyses.

For all three studies we defined birth cohorts based on reported age in the DHS and reported date of birth in the cohort studies. Ten-year birth cohorts, using 1950-9 as the baseline cohort, were used for the analysis. Later analysis using 5-year birth cohorts was restricted to those born after 1 January 1970 , whose first sex occurred when the prevalence of HIV was already high. The cohort born in 1970-4 was used as the baseline group for comparison.

For all data we smoothed the distribution by adding a random fraction of a year to each person's reported AFS to account for the time between their birthday and the date of first sex. With this approach it is possible to estimate summary measures for the population in increments of $<1$ year. Ten replications of each of the datasets were created using different simulations of the random fraction and the Stata command micombine was used for the formal comparisons. ${ }^{22}$

Age-to-event analysis (ie, survival before sexual debut) was used to summarise the median age and interquartile range (IOR) of AFS. Curves plotting the cumulative proportion who have had sex at any given age are used to display the pattern of sexual debut. ${ }^{23}$ Cox regression models (accounting for the survey design for DHS data; Stata Version 10) were used to look for changes in the median AFS by birth cohort. For the DHS data, these analyses were repeated for each survey and by selected background characteristics.

\section{RESULTS}

The number of male and female respondents in each of the DHS and from the Masaka and Rakai study by year of birth is shown in tables 1 and 2 . These tables also show the median AFS by birth cohort for each data source. From the DHS, a consistent increase in the median AFS was seen for women and a similar trend was apparent for young men. However, the composition of the DHS changes over time as each survey captures a different set of birth cohorts.

Survival curves by 10-year birth cohorts are shown in fig 1. Figure 1A combines the data from all four of the DHS, and the curves suggest that there has been a change towards a later AFS for women. The pattern of the change appears to be different for men and women: the female cohorts born in the 1980s appear to be delaying first sex from the outset, whereas there has been little change in the proportion of men who have had sex at the younger ages. The survival curves for women in the Masaka study (fig 1B) and the Rakai study (fig 1C) show a similar pattern to those from the DHS, with the female cohorts of the 1970s, 1980s and 1990s showing a delay in AFS. In Masaka women the AFS is slightly higher than that reported in the DHS study and in the Rakai cohort (table 2 and fig 1), and the delay in AFS among the 1980s birth cohort appears to be smaller in the Rakai cohort than in the DHS data and the Masaka cohort. For men, there seems to be some delay in AFS in the 1970s and 1980s birth cohorts in Masaka, but an earlier AFS in the 1980s birth cohort in Rakai (fig 1).

Table 3 translates these survival curves into relative hazards for the 10-year birth cohorts taking a baseline of those born in 1950-9. There is strong evidence from the DHS and the Masaka study that women in the 1980s and 1990s cohorts are starting sex later, with significantly lower relative hazards for those born in the 1970s, 1980s and 1990s compared with the baseline cohort of the 1950s. For the women in Rakai a significantly lower hazard is seen for the cohort born in the 1970s, but there was no significant difference in hazard for starting sex between those born in the 1980s and those born in the 1950s. For men, both the DHS and the Masaka study showed a trend towards delayed AFS in the later birth cohorts, but the only significant effects were seen in Masaka with a higher relative hazard in those born in the 1970s and a lower hazard in those born in the 1990s. Conversely, the trend in Rakai was towards an earlier AFS, with a significantly higher relative hazard in the cohort born in the 1980s compared with those born in the 1950s.

In restricting the analysis to those born after 1 January 1970 , the survival curves for 5 -year birth cohorts are shown in fig 2 and the relative hazards in table 4. In the DHS and Masaka studies, men and women in the later cohorts (those born in 1980-4 and 1985-9) had delayed AFS (fig 2). The Rakai data show the opposite, with the later cohorts having earlier AFS. This pattern is clearly seen in the hazard ratios for AFS in table 4, which shows increased hazard in the later cohorts in Rakai but reduced hazards in the DHS and Masaka studies.

Using data from the DHS, restricted to those born after 1 January 1970, comparisons can be made between those with different characteristics (table 5). AFS was delayed in later female birth cohorts, with a similar highly significant pattern in all regions (table 5). The delay in AFS was not seen in women with secondary education and was much smaller in women in the richest quintile. For men a smaller overall effect was seen (table 4). The delay in AFS in men born in the 1980s was seen as significant in urban areas and in those with no education (table 5).

\section{DISCUSSION}

Results from the DHS and from the Masaka study show a clear trend towards a delay in starting sex among women in Uganda, with those born in the 1980s reporting AFS about 1 year later than those born in the 1950s. A smaller delay was seen among women in Rakai who were born in the 1970s and the 1980s compared with those born in the 1950s. The change in AFS in men is less clear; in the DHS data no significant difference was seen between any of the male birth cohorts, and little evidence of a delay in AFS in either Masaka or Rakai. In the latest birth cohorts (born in the 1990s), the data from both DHS and Masaka indicate the possibility that AFS has been delayed even further in both women and men. However, this was based on small numbers and needs further follow-up to confirm the findings. These findings agree with other analyses of changes in sexual behaviour in young people in sub-Saharan Africa ${ }^{67}$ and in Uganda. ${ }^{13} 14$

By looking at the whole of the survival function rather than just the median AFS, it is clear that the pattern of change has been different for men and women and that the youngest women in the more recent cohorts are delaying sex but their male counterparts are not. In all graphs the women have sexual debut over a shorter period of time than the men, with many birth cohorts showing that some men are still virgin at the age of 25 years. This may show the choice that men have about sexual debut which may be denied to women, either through social pressure or through coercive sex.

The DHS findings show that the changes in the last 20 years have been greatest in those in the middle income quintiles and those with lower education (primary school or lower). This may be partly because more wealthy/highly educated young women have always been able to delay sexual debut, and it is only recently that the less wealthy and less educated have been able to access the same choices. The median AFS for women born in the 1970s who had secondary education and were in the richest 

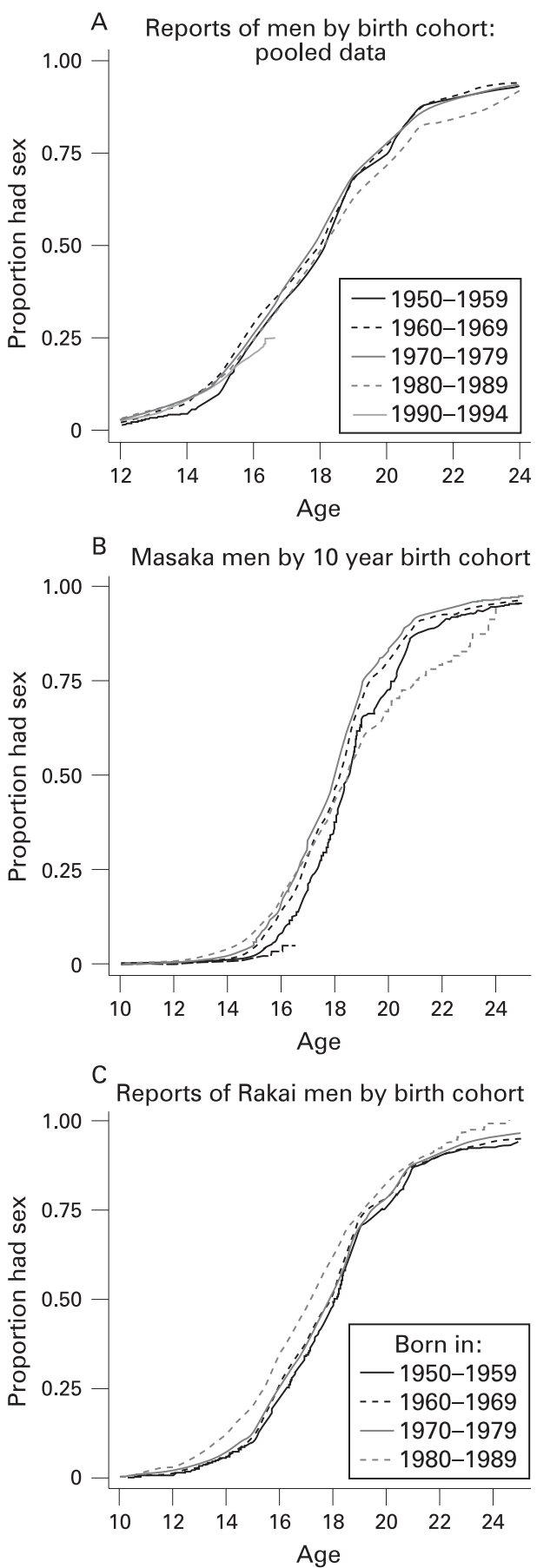

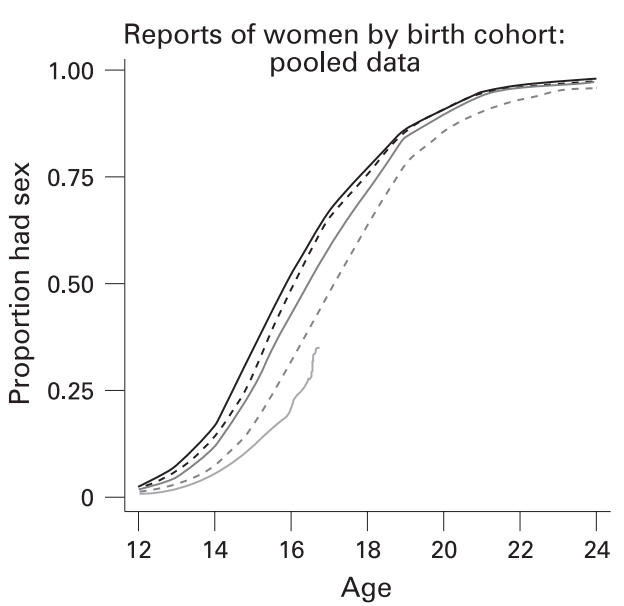

Masaka women by 10 year birth cohort

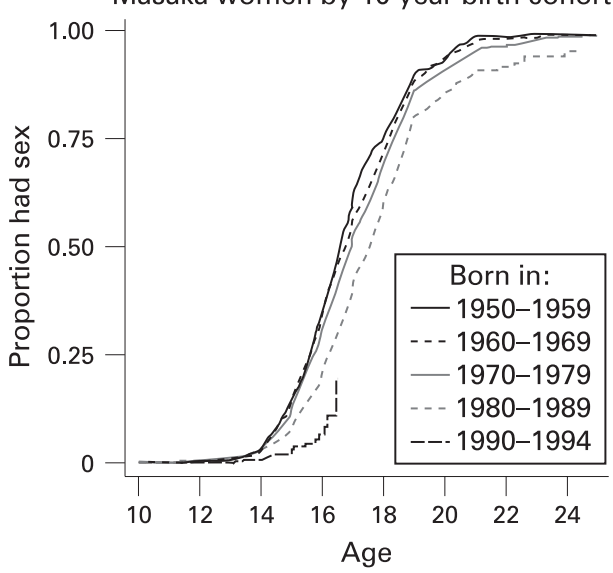

Reports of Rakai women by birth cohort

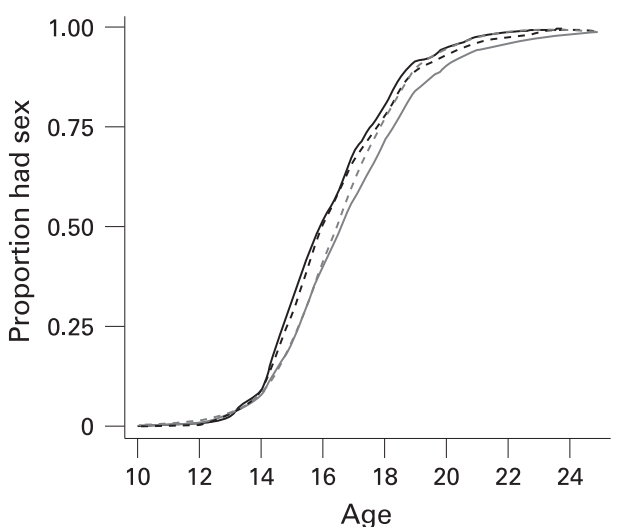

Figure 1 Survival curves (cumulative proportion that has had sex by age) for men and women by 10-year birth cohorts. (A) Pooled Demographic and Health Survey data; (B) Masaka study; (C) Rakai study.

quintile was 18.2 years compared with 16.3 years for all other women.

The timing of the observed changes in AFS relative to the decline in the prevalence of HIV in the early to mid 1990s (see fig S1 in the online supplement ${ }^{24-30}$ ) suggest that these changes have been a response to the danger of HIV infection, not a cause. To illustrate this, the survival functions can be plotted over calendar time. Based on DHS data, in 1980, 22\% of 14-16year-old women had had sex; in 1990 this had declined slightly to $20 \%$, but had halved by 2000 .

Changes in AFS may have helped to further reduce the incidence but cannot have been a cause of the initial decline.
Young women need the knowledge and ability to delay first sex. Regardless of the contribution to HIV prevention, if women in Uganda are increasingly able to delay first sex, this would be a major achievement for the health messages that have been used over the last 20 years.

The changes in reported AFS in the Rakai study are different from those seen in the DHS and the Masaka study. There is some evidence that delaying AFS started earlier in Rakai, with women born in the 1970s who started sex in the late 1980s and early 1990s showing later AFS than those born in the 1950s. This could have occurred because the prevalence of HIV was higher at an earlier date and the preventive action by young 
Table 3 Crude hazard ratios (HRs) from Cox regression models showing the effect of 10-year birth cohorts on survival time to first sex (data from pooled DHS, Masaka study and Rakai study)

\begin{tabular}{|c|c|c|c|c|c|c|}
\hline \multirow[b]{2}{*}{ Year of birth } & \multicolumn{2}{|l|}{ DHS } & \multicolumn{2}{|l|}{ Masaka } & \multicolumn{2}{|l|}{ Rakai } \\
\hline & Crude HR & p Value & Crude HR & p Value & Crude HR & p Value \\
\hline \multicolumn{7}{|l|}{ Men } \\
\hline $1950-9$ & 1 & & 1 & & 1 & \\
\hline $1960-9$ & $1.08(0.98$ to 1.19$)$ & 0.130 & $1.19(1.06$ to 1.33$)$ & 0.004 & $1.03(0.95$ to 1.11$)$ & 0.5 \\
\hline $1970-9$ & $1.08(0.99$ to 1.18$)$ & 0.096 & $1.29(1.15$ to 1.44$)$ & $<0.001$ & $1.05(0.98$ to 1.13$)$ & 0.16 \\
\hline $1980-9$ & $0.93(0.83$ to 1.05$)$ & 0.253 & $0.98(0.87$ to 1.11$)$ & 0.79 & $1.61(1.49$ to 1.74$)$ & $<0.001$ \\
\hline $1990-4$ & $0.86(0.61$ to 1.21$)$ & 0.383 & $0.32(0.19$ to 0.64$)$ & $<0.001$ & - & - \\
\hline Total & 6113 & & 5655 & & 11211 & \\
\hline \multicolumn{7}{|l|}{ Women } \\
\hline $1950-9$ & 1 & & 1 & & 1 & \\
\hline $1960-9$ & 0.94 (0.9 to 0.99$)$ & 0.017 & 0.92 (0.83 to 1.02 ) & 0.11 & $0.96(0.89$ to 1.03$)$ & 0.3 \\
\hline $1970-9$ & $0.87(0.83$ to 0.92$)$ & $<0.001$ & $0.83(0.75$ to 0.91$)$ & $<0.001$ & $0.81(0.76$ to 0.87$)$ & $<0.001$ \\
\hline $1980-9$ & $0.67(0.63$ to 0.71$)$ & $<0.001$ & 0.62 (0.57 to 0.69$)$ & $<0.001$ & $1.03(0.96$ to 1.11$)$ & 0.36 \\
\hline $1990-4$ & 0.37 (0.3 to 0.44$)$ & $<0.001$ & $0.23(0.15$ to 0.35$)$ & $<0.001$ & - & - \\
\hline Total & 26531 & & 6880 & & 14808 & \\
\hline
\end{tabular}

DHS, Demographic and Health Survey.

women was initiated in an earlier birth cohort. However, the effect in the latest birth cohort of men in Rakai shows earlier AFS and does not fit with the explanation that changes in the sexual debut of young people are a response to the HIV infection seen in the community. The result of the changes in the most recent cohorts is a more similar experience for young men and women, around one-quarter of whom have started sex by about the age of 15 years in Rakai. Sex between partners of different ages can be a risk for HIV infection. ${ }^{31}{ }^{32}$ The availability of more sexually active young men may reduce age mixing in this community if young women increasingly choose partners close to their own age. This may be beneficial for HIV prevention, although any effect may be transient and dependent on other characteristics of the partnership networks. ${ }^{33}$ The difference seen between the Rakai and Masaka cohorts could be due to the inclusion of trading centres in the Rakai study which are not seen in Masaka, as these may provide some employment to younger single women and men, and keep them in the study area. Single men aged 15-24 years comprised 25\% of the Masaka cohort and 29\% of the Rakai cohort in 2006. Single women of the same age made up $21 \%$ of the Masaka cohort and just $18 \%$ of the Rakai cohort at the same time. The overall proportions of young single people and the sex ratios were therefore different between the cohorts.

There are several limitations to these analyses. We have combined data from repeated cross-sectional DHS and two cohort studies. There may be selection biases in the DHS, but these should not be present in the cohort studies. ${ }^{23}$ Different questionnaires were used for each data source. In the Rakai study, AFS was only asked at the enrolment into the cohort at round 4 and during rounds $6-10$, so we have more information on some respondents. However, this is entirely at random as recruitment to the cohort is not related to first sex.

Others have shown that the quality of reporting of AFS can be variable and inconsistent, but this can be in either direction and should have no effect on the overall estimates. ${ }^{18}$ All data may be affected by social desirability bias as there have been extensive media campaigns in Uganda promoting safe sex and abstinence, but this should be similar across all sources. Although there have been health messages promoting abstinence and safe

Table 4 Crude hazard ratios (HRs) from Cox regression models showing the effect of 5-year birth cohorts on survival time to first sex (data from pooled DHS, Masaka study and Rakai study)

\begin{tabular}{|c|c|c|c|c|c|c|}
\hline \multirow[b]{2}{*}{ Year of birth } & \multicolumn{2}{|l|}{ DHS } & \multicolumn{2}{|l|}{ Masaka } & \multicolumn{2}{|l|}{ Rakai } \\
\hline & Crude HR & p Value & Crude HR & p Value & Crude HR & p Value \\
\hline \multicolumn{7}{|l|}{ Men } \\
\hline $1970-4$ & 1 & & 1 & & 1 & \\
\hline $1975-9$ & 0.99 (0.89 to 1.1$)$ & 0.81 & $1.02(0.91$ to 1.15$)$ & 0.7 & $1.10(1.03$ to 1.17$)$ & 0.002 \\
\hline $1980-4$ & 0.88 (0.77 to 1.0$)$ & 0.059 & $0.94(0.83$ to 1.06$)$ & 0.29 & 1.59 (1.49 to 1.71$)$ & $<0.001$ \\
\hline $1985-9$ & 0.82 (0.70 to 0.96$)$ & 0.011 & 0.51 (0.44 to 0.59 ) & $<0.001$ & 1.58 (1.42 to 1.76$)$ & $<0.001$ \\
\hline $1990-4$ & 0.8 (0.57 to 1.12$)$ & 0.187 & 0.21 (0.12 to 0.34$)$ & $<0.001$ & - & - \\
\hline Total & 3662 & & 4398 & & 8013 & \\
\hline \multicolumn{7}{|l|}{ Women } \\
\hline $1970-4$ & 1 & & 1 & & 1 & \\
\hline $1975-9$ & 0.97 (0.92 to 1.03$)$ & 0.301 & $0.93(0.84$ to 1.02$)$ & 0.13 & 0.94 (0.89 to 0.99$)$ & 0.016 \\
\hline $1980-4$ & 0.82 (0.77 to 0.86$)$ & $<0.001$ & 0.84 (0.76 to 0.93$)$ & 0.001 & 1.20 (1.13 to 1.26$)$ & $<0.001$ \\
\hline $1985-9$ & 0.67 (0.62 to 0.73 ) & $<0.001$ & 0.54 (0.48 to 0.61$)$ & $<0.001$ & 1.37 (1.27 to 1.49$)$ & $<0.001$ \\
\hline $1990-4$ & 0.44 (0.37 to 0.54$)$ & $<0.001$ & $0.27(0.18$ to 0.41$)$ & $<0.001$ & - & - \\
\hline Total & 15734 & & 5328 & & 11707 & \\
\hline
\end{tabular}

Restricted to those born on or after 1 January 1970.

DHS, Demographic and Health Survey. 

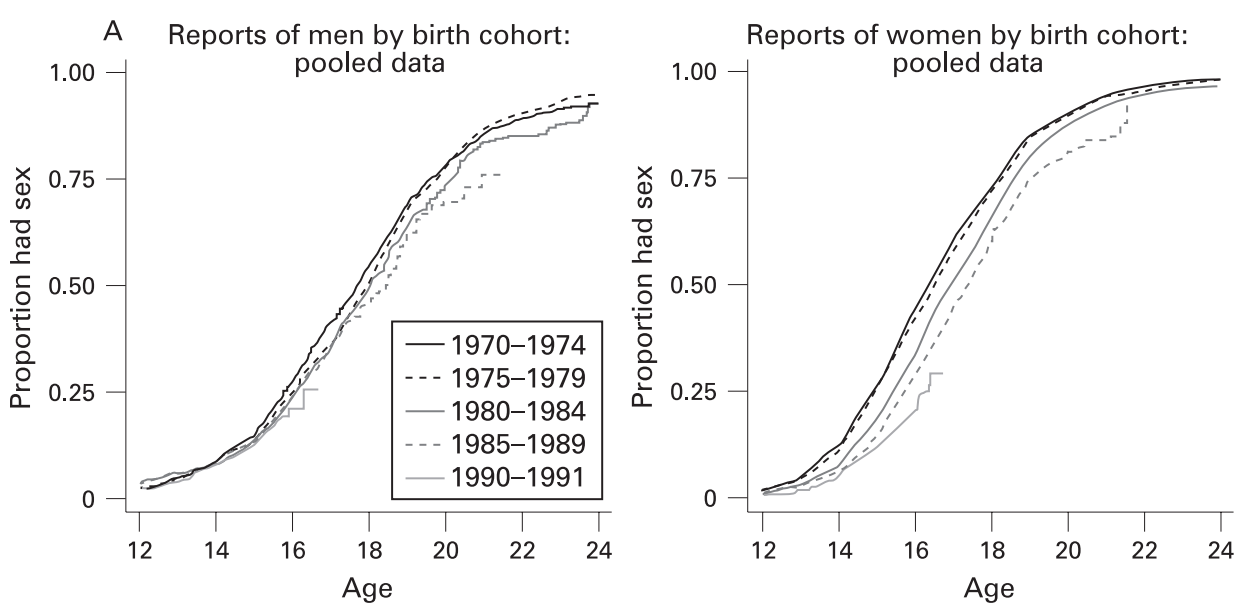

B Masaka men by 5 year birth cohort
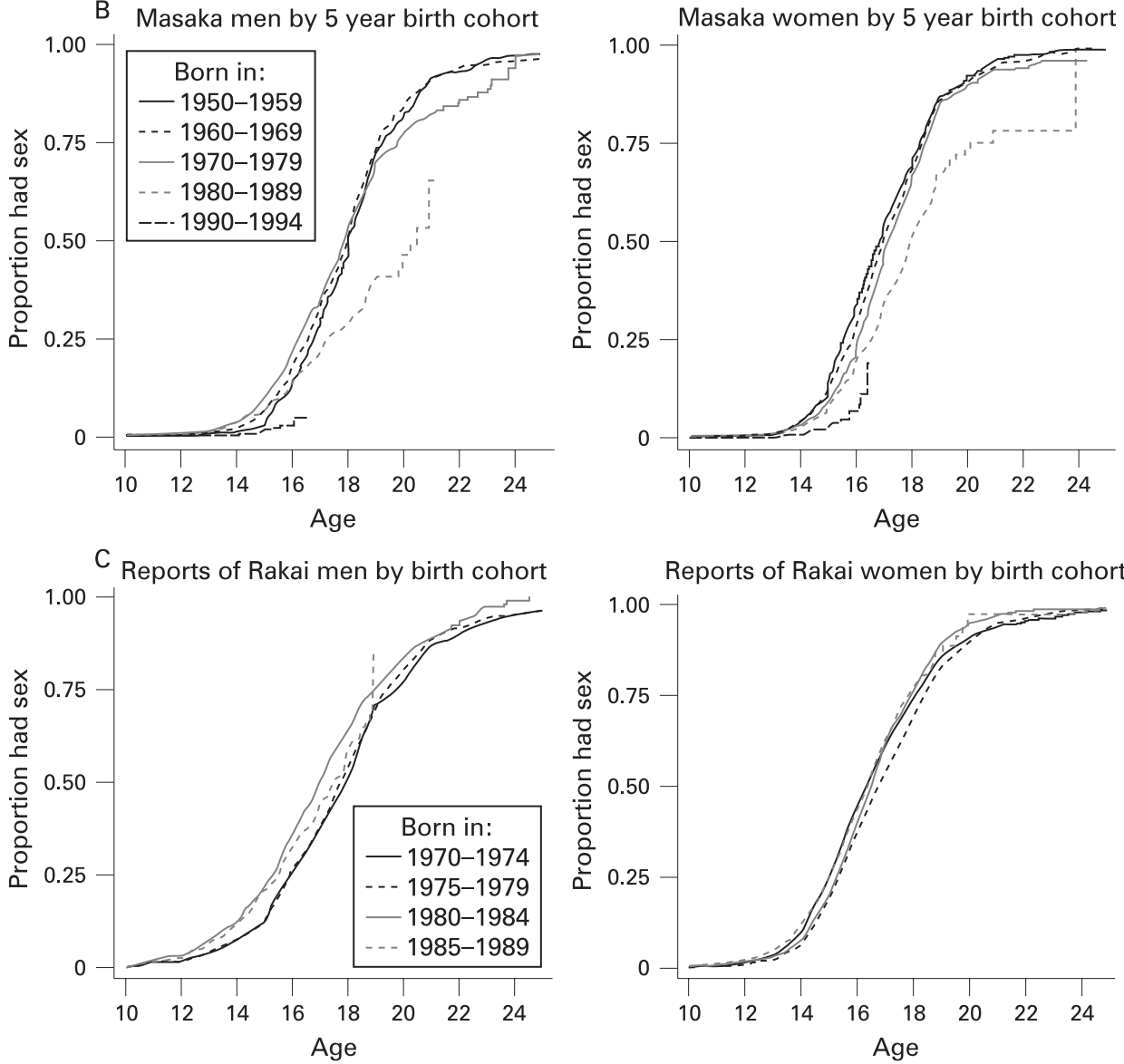

Figure 2 Survival curves (cumulative proportion who have had sex by age) for men and women born since 1970 by 5 -year birth cohorts. (A) Pooled Demographic and Health Survey data; (B) Masaka study; (C) Rakai study.

sex in Uganda, we did not see any difference in the responses of the same birth cohort over the four rounds of the DHS, which may indicate a limited bias due to social desirability. This effect may be more pronounced in the two cohort studies where the same people are seen every year and any messages would be reinforced over time, but there is no evidence for this in the Masaka data. ${ }^{18}$

A limitation of the cohort studies is the migration of young people from rural areas after completion of school. In Masaka, most young people (especially girls) do not remain at home, but either get married or migrate to larger towns or trading posts to search for work. This may skew the proportion of sexually active young women that remain in the cohort and may artificially raise the AFS if those who leave are never recruited into the cohort and have a younger AFS than cohort members.

\section{Take-home messages}

- Ugandan women born since the 1970s have started sex later than their predecessors.

- Change in men's age at first sex has not been directional.

- Changes in age at first sex are unlikely to have contributed to the initial decline in the prevalence of HIV in Uganda. 
Table 5 Hazard ratios (HRs) from Cox regression models showing the effect of 5-year birth cohorts on survival time to first sex (for pooled DHS data), stratified for area of residence, region, education and wealth

\begin{tabular}{|c|c|c|c|c|c|c|}
\hline & \multirow{2}{*}{$\begin{array}{l}\text { Median AFS } \\
\text { 1970-4 cohort }\end{array}$} & \multicolumn{5}{|c|}{ HRs by birth cohort } \\
\hline & & $1970-4$ & $1975-9$ & $1980-4$ & $1985-9$ & $1990-1$ \\
\hline \multicolumn{7}{|l|}{ Men } \\
\hline All subjects (HR) & 17.7 & 1 & 0.99 & 0.88 & $0.82 *$ & 0.8 \\
\hline \multicolumn{7}{|l|}{ Area (urban/rural) } \\
\hline Urban & 17.1 & 1 & $0.78^{*}$ & $0.76^{*}$ & $0.69 *$ & 0.48 \\
\hline Central $\dagger$ & 17.5 & 1 & 0.95 & 0.99 & 0.96 & 0.64 \\
\hline Eastern & 17.0 & 1 & 0.97 & 0.82 & $0.63^{*}$ & $0.43^{*}$ \\
\hline Northern & 18.2 & 1 & 1.22 & 0.95 & 1.14 & $1.62^{*}$ \\
\hline Western & 18.0 & 1 & 0.90 & $0.72^{*}$ & $0.67^{*}$ & 0.8 \\
\hline \multicolumn{7}{|l|}{ Education } \\
\hline None & 17.6 & 1 & 0.87 & 0.88 & 0.39 & $\mathrm{~N} / \mathrm{A}$ \\
\hline Poor & 18.4 & 1 & $1.36^{*}$ & 1.19 & 0.96 & 0.75 \\
\hline Middle & 17.7 & 1 & 0.82 & 0.93 & 0.84 & 0.71 \\
\hline Rich & 15.7 & 1 & 0.82 & 0.79 & 0.73 & 0.93 \\
\hline Richest & 16.2 & 1 & 0.93 & 0.87 & 1.0 & 0.75 \\
\hline \multicolumn{7}{|l|}{ Year of survey } \\
\hline 1995 & 17.5 & 1 & 0.92 & 0.51 & - & - \\
\hline 2001 & 18.1 & 1 & 1.02 & 0.95 & 0.6 & - \\
\hline 2006 & 17.6 & 1 & 0.97 & 0.9 & $0.83^{*}$ & 0.85 \\
\hline \multicolumn{7}{|l|}{ Women } \\
\hline All subjects (N) & & 4893 & 4532 & 3454 & 2101 & 754 \\
\hline All subjects (HR) & 16.4 & 1 & 0.97 & $0.82^{* * *}$ & $0.67^{* * *}$ & $0.44^{* * *}$ \\
\hline \multicolumn{7}{|l|}{ Education } \\
\hline None & 15.9 & 1 & 0.99 & 0.98 & 0.77 & 0.41 \\
\hline Primary & 16.2 & 1 & 1.04 & $0.81 * * *$ & $0.7^{* * *}$ & $0.42^{* * *}$ \\
\hline Secondary and above & 17.9 & 1 & 0.92 & 0.94 & 0.87 & 0.91 \\
\hline \multicolumn{7}{|l|}{ Wealth ranking } \\
\hline Poorest & 16.0 & 1 & 1.05 & 0.94 & 0.82 & 0.35 \\
\hline Poor & 16.3 & 1 & 0.99 & 0.91 & $0.78 * *$ & $0.36 * * *$ \\
\hline Middle & 15.1 & 1 & 1.09 & $0.83 * *$ & $0.6^{* * *}$ & $0.45^{* *}$ \\
\hline Rich & 15.0 & 1 & 0.9 & $0.7^{* * *}$ & $0.57^{* * *}$ & $0.43^{* * *}$ \\
\hline Richest & 17.1 & 1 & 1 & 0.88 & $0.76 * *$ & 0.75 \\
\hline \multicolumn{7}{|l|}{ Year of survey } \\
\hline 1995 & 16.3 & 1 & 0.98 & 0.67 & & \\
\hline 2001 & 16.6 & 1 & 1.04 & $0.89 *$ & $0.56^{* * *}$ & - \\
\hline 2006 & 16.2 & 1 & 0.93 & $0.8 * * *$ & $0.65^{* * *}$ & $0.42^{* * *}$ \\
\hline
\end{tabular}

Restricted to those born on or after 1 January 1970.

All birth cohorts compared with those born in 1970-4.

${ }^{*} \mathrm{p}<0.05 ;{ }^{* *} \mathrm{p}<0.01 ;{ }^{* * *} \mathrm{p}<0.001$.

$\dagger$ Central region contains Masaka and Rakai districts.

All three studies cover a large population, so the effects we see have tight confidence limits and should give an accurate picture of any real changes in reported AFS in Uganda. The three studies indicate that large changes in AFS have been seen in women over the last 20 years. These changes may be influenced by the HIV epidemic seen in
Uganda, but are unlikely to be the factor which explains the decline in HIV prevalence seen in Uganda in the 1990s. It is more likely that this is a positive side effect of the empowerment of women, especially young women, so that they can make their own choices about when and with whom they initiate sex. 
Acknowledgements: The work in this paper was facilitated by a workshop run by the ALPHA network in Zimbabwe. The authors thank the organisers of the workshop for the ideas and help with the analysis and the writing of this paper. They also thank the project leaders and all the staff of the study sites for their help and for the use of the data; the participants in the studies and the communities for their forbearance and acceptance of the studies; and Leigh Anne Shafer and Richard White for providing the HIV prevalence data from the graphs in their papers.

Funding: The paper was written with financial support from the Medical Research Council of UK, Johns Hopkins School of Public Health and the Wellcome Trust through their support for the ALPHA network.

Competing interests: None.

Contributors: ES planned the analyses and analysed the DHS data. JT oversaw the analyses. JT, IK and DM analysed the Masaka data. TL and JBB analysed the Rakai data. All authors reviewed the results and wrote the paper.

\section{REFERENCES}

1. United Nations Programme on HIV/AIDS (UNAIDS). National AIDS programmes: a guide to monitoring and evaluation. 1st ed. Geneva: UNAIDS, 2000.

2. United Nations Programme on HIV/AIDS (UNAIDS). United Nations General Assembly Special Session on HIVIAIDS. Monitoring the declaration of commitment on HIVIAIDS. Guidelines on construction of core indicators. Geneva: Joint United Nations Programme on HIV/AIDS (UNAIDS), 2002.

3. United Nations Programme on HIV/AIDS (UNAIDS). Follow-up to the 2001United Nations General Assembly Special Session on HIVIAIDS: Progress report on the global response to the HIVIAIDS epidemic, 2003. Geneva: UNAIDS, 2003

4. Measure DHS. AIDS indicator database: list of indicators, 2008. http://www. measuredhs.com/hivdata/start.cfm

5. World Health Organization. National AIDS programmes: a guide to indicators for monitoring and evaluation national HIVIAIDS prevention programmes for young people. Geneva: World Health Organization, 2004.

6. Mensch B, Grant M, Blanc A. The changing context of sexual initiation in subSaharan Africa. Popul Dev Rev 2006;32:699-727.

7. Wellings $\mathbf{K}$, Collumbien M, Slaymaker $\mathrm{E}$, et al. Sexual behaviour in context: a global perspective. Lancet 2006;368:1706-28.

8. Marston C, King E. Factors that shape young people's sexual behaviour: a systematic review. Lancet 2006;368:1581-6.

9. Dickson N, Paul C, Herbison P, et al. First sexual intercourse: age, coercion and later regrets reported by a birth cohort. BMJ 1998;316:29-33.

10. Koenig MA, Lutalo T, Zhao F, et al. Coercive sex in rural Uganda: prevalence and associated risk factors. Soc Sci Med 2004;58:787-98.

11. Measure DHS. Demographic and health surveys, 2008. http://www.measuredhs. com

12. Kamali A, Carpenter LM, Whitworth JAG, et al. Seven-year trends in HIV-1 infection rates, and changes in sexual behaviour, among adults in rural Uganda. AIDS 2000;14:427-34.

13. Kirungi WL, Musinguzi J, Madraa E, et al. Trends in antenatal HIV prevalence in urban Uganda associated with uptake of preventive sexual behaviour. Sex Transm Infect 2006;82(Suppl I):i36-41.
14. Bessinger R, Akwara P, Halperin D. Sexual behavior, HIV, and fertility trends: a comparative analysis of six countries phase I of the ABC Study. Chapel Hill, North Carolina, USA: Measure Evaluation, 2003. http://www.cpc.unc.edu/measure/ publications/pdf/sr-03-21b.pdf

15. Green E, Halperin D, Nantulya V, et al. Uganda's HIV prevention success: the role of sexual behavior change and the national response. AIDS Behav 2006;10:335-46.

16. Singh S, Darroch JE, Bankole A. A, B and C in Uganda: the roles of abstinence, monogamy and condom use in HIV decline. Reprod Health Matters 2004;12:129-31.

17. Parkhurst $\mathbf{J}$. The Ugandan success story? Evidence and claims of HIV-1 prevention. Lancet 2002;360:78-80.

18. Wringe A, Cremin I, Todd J, et al. Comparative assessment of the quality of age-atevent reporting in three HIV cohort studies in sub-Saharan Africa. Sex Transm Infect 2009;85(Suppl I):i56-i63.

19. Mulder D, Nunn A, Wagner H, et al. HIV-1 incidence and HIV-1-associated mortality in a rural Ugandan population cohort. AIDS 1994;8:87-92.

20. Wawer M, Gray R, Sewankambo N, et al. A randomized, community trial of intensive sexually transmitted disease control for AIDS prevention, Rakai, Uganda. AIDS 1998;12:1211-25.

21. Wawer M, Sewankambo N, Serwadda D, et al. Control of sexually transmitted diseases for AIDS prevention in Uganda: a randomised community trial. Rakai Project Study Group. Lancet 1999;353:525-35.

22. Royston P. Multiple imputation of missing values: further update of ice, with an emphasis on interval censoring. Stata J 2007;7:445-64.

23. Żaba B, Pisani E, Slaymaker E, et al. Age at first sex: understanding recent trends in African demographic surveys. Sex Transm Infect 2004;80(Suppl II):iï28-35.

24. Ministry of Health/ORC Macro. Uganda HIVIAIDS sero-behavioural survey 2004-5. Calverton, Maryland, USA: Ministry of Health and ORC Macro, 2006.

25. United Nations Programme on HIV/AIDS (UNAIDS). Report on the global AIDS epidemic, 2004. Geneva: UNAIDS, 2004.

26. United Nations Programme on HIV/AIDS (UNAIDS). Report on the global AIDS epidemic, 2008. Geneva: UNAIDS, 2008

27. Shafer LA, Biraro S, Nakiyingi-Miiroa J, et al. HIV prevalence and incidence are no longer falling in southwest Uganda: evidence from a rural population cohort 19892005. AIDS 2008;22:1641-9.

28. White RG, Orroth KK, Korenromp EL, et al. Can population differences explain the contrasting results of the Mwanza, Rakai, and Masaka HIV/sexually transmitted disease intervention trials? J AIDS 2004;37:1500-13.

29. Omer S, Gray R, Kagaayi J, et al. 12-year trends in HIV prevalence, incidence, mortality and risk behaviours in a community based cohort in Rakai, Uganda: evidence of decreased HIV incidence, increased sexual risk behaviors offset by condom use. XVII International AIDS Conference; Mexico City; 3-8 Aug 2008.

30. Wawer M, Gray R, Serwadda D, et al. Declines in HIV prevalence in Uganda: not as simple as $A B C$. 12th Conference on Retroviruses and Opportunistic Infections; Boston, Massachusetts, USA; 2005.

31. Gregson S, Nyamukapa CA, Garnett GP, et al. Sexual mixing patterns and sexdifferentials in teenage exposure to HIV infection in rural Zimbabwe. Lancet 2002;359:1896-903.

32. Kelly RJ, Gray RH, Sewankambo NK, et al. Age differences in sexual partners and risk of HIV-1 infection in rural Uganda. J Acquir Immune Defic Syndr 2003;32:446-51.

33. Hallett TB, Gregson S, Lewis JJC, et al. Behaviour change in generalised HIV epidemics: impact of reducing cross-generational sex and delaying age at sexua debut. Sex Transm Infect 2007;83(Suppl I):i50-4. 